\section{"MUITO MAIS DO QUE UM JOGO": OS EMBATES ENTRE O COI E A FIFA PELO CONTROLE DO FUTEBOL OLIMPICO}

\author{
Sérgio Settani Giglio
}

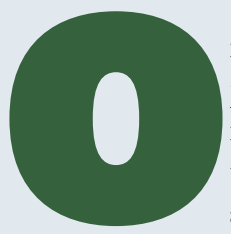

futebol é uma das modalidades mais antigas do programa olímpico. Sua importância no cenário futebolístico sofreu mudanças ao longo da existência dos Jogos Olímpicos da Era Moderna. Sua ausência em apenas duas ediçôes (1896 e 1932) revela que durante muito tempo o futebol teve nos Jogos Olímpicos a sua grande competição entre seleções.

Neste texto, tratarei do contexto político e algumas restrições pelas quais passou essa modalidade desde a sua primeira participação como modalidade exibição em 1900 até a última edição olímpica, em 1976, antes da criação da Copa do Mundo de Juniores (1977), atual Sub-20. O ano de 1976 funciona como um marco simbólico como forma de delimitar um período em que o Comitê Olímpico Internacional (COI) e a Federação Internacional de Futebol (Fifa) travaram inúmeras disputas em torno do futebol tendo como objetivo estabelecer quem detinha o controle do futebol. Tal fato representa a ação da Fifa em enfraquecer o futebol olímpico para valorizar o seu principal produto, a Copa do Mundo de Futebol.

Portanto, o objetivo deste artigo é analisar como, ao longo da história olímpica, o futebol se tornou um ponto de conflito entre o COI e a Fifa. Tal embate se revela nos dias atuais por meio de restrições impostas pela Fifa ao futebol olímpico como sendo uma de suas açôes para enfraquecê-lo. Em outras palavras, a Fifa gostaria que o futebol não estivesse no programa olímpico. Para o COI, a presença do futebol em sua competição é vista como uma excelente fonte de renda diante das médias de público obtidas nas recentes competições. Por trás dessa disputa está a busca pelo controle do futebol no mundo.

O FUTEBOL E OS JOGOS OLÍMPICOS (1896-1912) O futebol é uma das modalidades mais antigas do programa olímpico da Era Moderna. O COI foi criado em 1894, por iniciativa de seu idealizador Pierre de Coubertin, na Conferência Internacional na Sorbonne (1). Dois anos depois acontecia em Atenas, na Grécia, a primeira edição dos Jogos Olímpicos.

Nessa ocasião, o futebol não foi incluído no programa dos Jogos pelo fato de que nenhum país se interessou em enviar uma equipe para a disputa. Nos Jogos seguintes, Paris (1900) e Saint Louis (1904), os Jogos Olímpicos foram um anexo das Exposiçōes Universais que funcionava como um espaço de divulgação da modernidade (2). Nessas duas ediçōes poucos países enviaram suas equipes e o futebol foi incluído como modalidade de exibição e por tal fato a Fifa não apresenta essas duas edições em seu site. A ausência dessa competição nos arquivos online da Fifa também pode ser lida como uma forma de não validar essa competição antes de sua fundação, que aconteceu em 1904.
Apesar das competições esportivas terem ficado perdidas diante do grande número de eventos apresentados nas Exposiçóes (3), essa experiência serviu como um processo embrionário que permitiu aos Jogos Olímpicos crescer e criar a sua própria identidade.

Como forma de comemorar os dez anos da primeira edição olímpica aconteceram, novamente, em Atenas, os Jogos Intermediários. Essa competição é considerada de fundamental importância para o desenvolvimento do COI e como forma de fortalecer os ideais olímpicos (4;5). Mesmo após dois anos de sua criação, a Fifa não se interessou em participar do torneio olímpico (6).

Somente nos Jogos de Londres de 1908, o futebol foi incluído oficialmente no programa olímpico e a organização da competição coube à Fifa. Tendo como suporte a ideia dos princípios olímpicos foi ressaltado que somente poderiam participar atletas amadores, sendo considerado amador aquele que não recebesse remuneração ou consideração de qualquer espécie a mais do que as despesas necessárias para pagar hotel e viagem, ou aquele que não estivesse registrado como profissional.

Entre os Jogos de 1908 e 1912, o futebol ganhou espaço em vários países do mundo e com isso houve um aumento de praticantes. Dessa forma, com a popularidade do futebol, os trabalhadores passavam a representar uma ameaça aos princípios olímpicos. Reforçar a condição do atleta amador como sendo aquele que poderia praticar o esporte em seu tempo livre (os aristocratas) restringia a presença daqueles que tinham que trabalhar e, consequentemente, praticavam alguma modalidade em seu tempo livre. Portanto, nos Jogos de 1912 apareceu, pela primeira vez, o questionamento sobre a permanência do futebol no programa olímpico (7).

FUTEBOL E POLÍTICA NOS JOGOS OLÍMPICOS (1913-1936) A eclosão da Primeira Guerra Mundial (1914-1918) provocou o cancelamento dos Jogos de 1916. Após o fim do conflito os Jogos voltaram a acontecer em 1920 em Antuérpia. A década de 1920 ficou marcada por evidenciar uma série de elementos políticos presentes no esporte olímpico e, em especial, no futebol. Se a presença de reis, príncipes, barôes eram frequentes nos eventos esportivos um outro componente, o nacionalismo, passou a se manifestar com mais clareza nesses espaços. A final do futebol olímpico entre Bélgica e Tchecoslováquia é relatada por Dietschy (8) como sendo a exacerbação do sentimento nacional após uma divergência em um lance da partida. Para o autor, esse nacionalismo funciona como um dos principais fatores de manifestações de violência, simbólica ou real.

Os Jogos Olímpicos de Paris (1924) representam uma grande transformação na estrutura do futebol e confirma que o futebol havia se popularizado. $\mathrm{O}$ torneio de futebol foi disputado em quatro estádios diferentes (Colombes, Pershing, Berger e Paris) e, segundo o Relatório Oficial dos Jogos teve um público acumulado de 201.324 pessoas (9). Para Vigarello (10), a presença do estádio proporcionou o acesso das massas para acompanhar de perto as competições.

AMADORES VERSUS PROFISSIONAIS Ao final dos Jogos de 1924 se iniciou um debate entre o COI e a Fifa que foi crucial para os 
rumos do futebol dentro dos Jogos Olímpicos. O debate sobre a definição de amadorismo que seria definida envolvia o presidente do COI, Baillet-Latour, e o presidente da Fifa, Jules Rimet.

Um ano depois aconteceu o Congresso de Praga (1925) e a definição de amador foi feita em conjunto com as federações internacionais. Nesse debate, o COI se posicionou contrário à possibilidade dos atletas receberem compensação por perda de salário quando ficassem afastados (broken time) de suas atividades laborais para participar de alguma competição esportiva. A Fifa, por sua vez, passou a considerar (a partir de $1^{\circ}$ de outubro de 1925) como sendo atletas amadores somente aqueles que não recebiam compensação por perda de salário. Em 1927, a Fifa anunciou que resolveu estabelecer alguns critérios para o ressarcimento referente aos salários perdidos ocasionados por conta do afastamento. A Federação Internacional de Futebol queria colocar em igualdade de condições os jogadores-trabalhadores, especialmente, nos casos em que o empregador se recusasse a pagar o atleta pelo seu tempo de afastamento. E para que isso não acontecesse defendia que o empregador fosse reembolsado. Diante das discordâncias ficou estabelecido que a decisão sobre o afastamento e pagamento por salário perdido seria decidido em um próximo congresso.

O que estava por trás de todo esse debate era a obtenção do controle do futebol no mundo. Caso o COI aceitasse as imposiçōes da Fifa não teria como se posicionar diante das outras modalidades e caso a Fifa aceitasse a visão do COI tornar-se-ia uma entidade subordinada. Em suma, o que estava em jogo era o poder e na primeira grande divergência por ele, as quatro federaçōes britânicas se retiraram da Fifa (11).

Logo começaram as sondagens para eliminar o foco do problema: o futebol. Na 27 a sessão do COI, realizada poucos dias antes do término dos Jogos de Amsterdã, o comitê executivo fez a proposta de retornar ao programa original dos Jogos. O presidente do COI, Baillet-Latour, afirmou que se fosse estabelecida essa decisão duas modalidades estariam excluídas: o futebol e o tênis. Apesar das divergências, o futebol pôde participar dessa edição olímpica, mas o COI resolveu retirar o tênis do programa de 1928 quando a Federação Internacional de Tênis de Campo (Filt) proibiu seus atletas de competirem nos Jogos (12).

Todos esses embates revelam a crise pela qual passava o amadorismo que tinha, de um lado, o esporte como algo a ser realizado no tempo livre, algo destinado aos aristocratas; na outra ponta estava o trabalho e com ele os assalariados que não eram bem vistos dentro do movimento olímpico. Toda essa tensão está direcionada para o profissionalismo e as formas de impedir, ao menos pelo COI, que o esporte se tornasse o trabalho principal das pessoas.
Foto: Odebrecht/Divulgação

Ao final dos Jogos de 1928 ficou decidido que o futebol não faria parte do programa de 1932. Com a saída da modalidade e diante da autonomia que já apresentava em relação ao movimento olímpico, em outubro de 1928 a Fifa anunciou que pretendia organizar um campeonato mundial de futebol aberto para amadores e profissionais, mas que esse fato não iria interferir nos Jogos Olímpicos (13).

Em Los Angeles 1932, o futebol ficou de fora do programa, mas a discussão em torno das definiçōes de amador e profissional continuaram a acontecer. A Fifa retirou a definição de amador do seu estatuto e também as regras sobre o pagamento por perda de salário, ficando a cargo das federaçôes internacionais a responsabilidade por essas questóes. Em 1934, o futebol foi aceito novamente no programa olímpico. A Fifa concordou que os atletas participantes seriam os que não receberam reembolso por tempo de afastamento. Apesar da Fifa em seu congresso ter decidido pela presença do futebol nos Jogos Olímpicos, do lado do COI havia certa resistência por parte de Coubertin que defendia a valorização das modalidades individuais.

O retorno do futebol aos Jogos Olímpicos de 1936, em Berlim, ficou marcado por um conflito político entre Peru e Áustria. Durante a realização dessa partida aconteceu a invasão de campo de um torcedor que chutou um jogador austríaco. Após o incidente e com a derrota, a Áustria entrou com um recurso alegando que havia sido prejudicada. A Fifa montou uma comissão para julgar o caso, mas essa comissão foi composta apenas por membros europeus. A decisão dessa comissão indicou que deveria ser realizada uma nova partida entre as seleçóes, fato que desagradou a delegação peruana que, por sua vez, acusou a Fifa de ter tomado uma decisão ditatorial. O Peru discordou da decisão e informou que se fosse mantida tal decisão o país retiraria todos os seus atletas dos Jogos (14). Com a retirada do Peru havia uma expectativa de que outros países da América do Sul também se retirariam em solidariedade. Tal apoio não aconteceu de forma completa.

Esse episódio explicita a visão eurocêntrica das entidades que regiam os Jogos Olímpicos e o torneio de futebol. As decisões estavam concentradas nas mãos de poucos europeus. A ação política em retirar todos os atletas e não somente a equipe de futebol era uma forma de discordar do modelo esportivo estabelecido. Essa coragem de enfrentar os sistemas esportivo e político, ainda mais no contexto dos Jogos de Hitler, evidenciava o quanto a América do Sul não estava organizada do ponto de vista político para conquistar um espaço no campo esportivo e, portanto, acatavam as "decisōes ditatoriais" que definiam os rumos do esporte no mundo ou nas palavras de Bourdieu (15) como estava constituído o campo esportivo. 
APÓS A SEGUNDA GUERRA MUNDIAL O NOVO PALCO DO FUTEBOL SERÁ A COPA DO MUNDO E NÃO MAIS OS JOGOS OLÍMPICOS (1948-

1976) A interrupção provocada pela Segunda Guerra Mundial impediu a realização de duas edições olímpicas (1940-1944). Em seu retorno, em 1948, o futebol continuou no programa olímpico enquanto a Copa do Mundo caminha para a sua quarta edição e foi nessa nova fase que aconteceu um aumento do interesse pelo evento promovido pela Fifa.

Os Jogos Olímpicos retornaram a Londres após 40 anos e o cenário dessa nova edição olímpica era bem diferente de 1908. Algumas seleçōes não participaram do torneio de futebol por alegar que o futebol profissional havia ganhado espaço em seu país e, por tal fato, não teriam condições de enviar uma seleção competitiva para a disputa. Continuavam vigentes as regras do amadorismo que ressaltava o interesse do atleta em praticar o esporte por prazer sem que houvesse algum tipo de ganho financeiro.

Toda essa estrutura que colocava o amadorismo e o profissionalismo em lados opostos também passou a polarizar o mundo esportivo a partir dos países capitalistas e socialistas. Como nos países socialistas não havia profissionalismo, os atletas eram contratados como funcionários do Estado para poderem participar das competiçōes esportivas.

Mesclada a essa condição algumas seleções, que disputariam os Jogos de Helsinque em 1952, eram acusadas de possuir atletas profissionais em suas equipes. Diante dessa situação, o então presidente da Fifa, o inglês Stanley Rous, defendia a saída do futebol do programa olímpico.

Apesar desse posicionamento, o futebol passou a integrar o programa obrigatório dos Jogos Olímpicos de Melbourne em 1956. A discussão em torno do amadorismo e profissionalismo continuava a acontecer no COI. O presidente da entidade, o norte-americano Avery Brundage, defensor do amadorismo, procurava de todas as formas impedir que os Jogos Olímpicos funcionassem como um trampolim para os atletas amadores se tornarem profissionais. Em uma de suas ações, Brundage queria obrigar os atletas a declararem que não iam se tornar profissionais no futuro. Essa medida polêmica foi desconsiderada pelo COI (16).

O futebol nos Jogos de 1956 ficou marcado pela desistência de algumas seleçōes e algumas críticas foram feitas, especialmente, pela imprensa estrangeira em relação à duração da competição dessa modalidade e da partida final ter acontecido no último dia do evento. Com base nesses argumentos a imprensa colocava-se a favor da saída do futebol do programa olímpico.

Para os Jogos Olímpicos de Roma em 1960 a Fifa tomou uma decisão inédita: estava proibida, além dos atletas profissionais, a participação dos jogadores que haviam disputado a Copa do Mundo da Suécia de 1958. Essa determinação foi apresentada como forma de salvar o torneio olímpico e, consequentemente, restringir o acesso dos atletas pertencentes aos países que não reconheciam o profissionalismo (União Soviética, Suécia, Tchecoslováquia e Hungria) e tinham um grande êxito nessa competição.

Quatro anos depois, nos Jogos de Tóquio de 1964, o futebol continuava sem grande prestígio dentro do COI. Em uma consulta interna, 83,5\% dos 67 membros consultados da entidade defendiam que o futebol deveria ser retirado do programa olímpico. Entre os argumentos destacavam-se: após a criação da Copa do Mundo o futebol olímpico precisava possuir um maior alcance; diante das regras estabelecidas, após a Segunda Guerra, os campeōes foram invariavelmente os países que não adotavam o profissionalismo e, pela primeira vez, apareceu o argumento de que seria necessário estabelecer um limite de idade como forma de valorizar os jovens jogadores.

Seguindo as linhas de restriçōes nesse jogo de poder entre as duas entidades, a Fifa estabeleceu que não poderiam participar dos Jogos de Tóquio os atletas amadores da Europa e da América do Sul que haviam disputado as eliminatórias e/ou a Copa do Mundo de 1962 no Chile.

Nesse cenário as dificuldades passavam, principalmente, por estabelecer (ou fiscalizar) quem era o atleta amador. Embora Rous, presidente da Fifa, declarasse que $99 \%$ dos jogadores eram amadores naquele momento o cenário de denúncias feitas aos falsos amadores fazia com que Brundage, presidente do COI, pedisse maior fiscalização por parte da Fifa. E, nesse jogo de poder entre as entidades, Brundage alertava que se houvesse alguma divergência entre as regras da Fifa e do COI que deveriam ser seguidas as do COI.

Alguns anos antes dos Jogos do México de 1968, a discussão sobre amadores e profissionais continuava na pauta do futebol. Muitos defendiam que o futebol por ser um esporte popular deveria continuar no programa, mas que deveria existir um controle maior sobre os amadores. A Fifa apresentou uma proposta para criar uma comissão amadora encarregada exclusivamente de cuidar do futebol amador. Porém, de acordo com Rous, essa nova comissão atuaria somente na Europa e América do Sul, pois na África e na Ásia o futebol profissional praticamente não existia.

O futebol nos Jogos de Munique de 1972 chegava sob a desconfiança de que algumas seleçōes haviam infringido as regras do amadorismo nos Jogos de 1968, pois muitos atletas já tinham recebido dinheiro para jogar futebol. Brundage entendia que o futebol tinha conquistado o seu espaço com a Copa do Mundo e o futebol nos Jogos Olímpicos ficava com a parte que sobrava desse interesse. Ainda criticava o excesso do número de partidas dessa modalidade dentro dos Jogos. Para ele, a única forma de manter intacto os ideais amadores era manter o evento restrito aos amadores e longe da comercialização. Diante do modo como o presidente do COI tratava o futebol, Rous ameaçava com a possibilidade de criar uma Copa do Mundo para amadores.

Os Jogos Olímpicos de Montreal em 1976 colocaram na pauta do COI o problema do tamanho do evento. Killanin, presidente do COI que havia assumido ao final dos Jogos de 1972, aos poucos, implantava a sua visão dentro do movimento olímpico. Após muitos anos de disputas e discordâncias, o COI também passou a permitir, com o consentimento de alguma entidade esportiva, que o atleta pudesse ser reembolsado. Essa ação indicava que o COI estava em busca de uma nova imagem deixando de lado a visão que havia se tornado uma entidade obsoleta.

Em 1974, o brasileiro João Havelange assumiu a presidência da Fifa e, embora tecesse elogios aos Jogos Olímpicos, teve como 
proposta de sua gestão valorizar o principal produto da entidade - a Copa do Mundo - em detrimento dos Jogos Olímpicos. Para concretizar essa ação criou a Copa do Mundo de Juniores, atual Sub20, para incentivar, desde cedo, a vontade dos jovens jogadores em fazerem parte de uma Copa do Mundo.

CONSIDERAÇÕES FINAIS Ao longo de sua história os Jogos Olímpicos se solidificaram como um grande evento esportivo e, atualmente, é capaz de atrair a atenção do mundo inteiro. Devido a esse crescimento inúmeras questôes pontuaram as reuniões do $\mathrm{COI} e$, diante da dimensão que o evento conquistou, tornou-se um espaço para a disputa de poder.

O futebol inserido inicialmente como modalidade exibição nos Jogos de 1900 e 1904 logo conquistou espaço nos Jogos Olímpicos, sob o lema do amadorismo. Foi, no entanto, exatamente pelas divergências entre as definiçōes de amadorismo que se estabeleceu uma série de debates e divergências entre o $\mathrm{COI}$ e a Fifa. O resultado dessas disputas em torno das definiçōes fez com que a Fifa criasse a sua própria competição, a Copa do Mundo (11).

A modalidade, frequentemente, passou por questionamentos por parte dos próprios membros do COI e de alguns presidentes que não a consideravam como algo importante dentro dos Jogos. Aproveitando-se de todo esse quadro, em 1974, quando João Havelange assumiu a Fifa ele tinha outros planos para o futebol.

Havelange, como um excelente estrategista e conhecendo muito bem o campo esportivo (12) do qual fazia parte, montou um plano de ação para fortalecer seu principal produto, a Copa do Mundo, e desvalorizar o produto do COI, o futebol olímpico. Para isso, investiu na criação da Copa do Mundo de Juniores.

Nessa lógica para motivar o desejo dos jovens em participarem da Copa do Mundo e não dos Jogos Olímpicos, estabeleceu que o evento para os juniores deveria acontecer a cada dois anos e suas sedes foram, majoritariamente, em países com pouca tradição na Copa do Mundo mas com grande presença no torneio olímpico.

Os atletas profissionais do futebol foram aceitos em 1984 dentro do programa olímpico. Oito anos depois ficou decidido que apenas os atletas Sub-23 poderiam participar do torneio olímpico. Após mais um espaço de discussões entre o COI e a Fifa ficou estabelecido que poderiam participar até três jogadores acima desse limite de idade. Em suma, nesse jogo político entre o COI e a Fifa e diante das inúmeras restriçōes pelas quais passou o futebol pode-se afirmar que ambas entidades estavam em busca do poder e, portanto, do controle do futebol no mundo.

Sérgio Settani Giglioé doutorem ciências pela Escola de Educação Físicae Esporte da Universidade de São Paulo (USP), professor do curso de educação fisica da Universidade Nove de Julho e um dos editores do site Ludopédio (www.ludopedio.com.br).

\section{NOTAS E REFERÊNCIAS BIBLIOGRÁFICAS}

1. Lucas, J. A. "Olympic genesis: the Sorbonne Conferences of 1892 and 1894". Olympic Review, n. 85-86, novembro - dezembro de 1974, p. 607-610.

2. Ortiz, R. Mundialização e cultura. São Paulo: Brasiliense, 2000.
3. Rubio, K. "Jogos Olímpicos da Era Moderna: uma proposta de periodização". Revista Brasileira de Educação Física e Esporte, São Paulo, v. 24, n. 1, p. 55-68, 2010.

4 Krüger, A. "The unfinished symphony: a history of the Olympic Games from Coubertin to Samaranch". In: Riordan, J.; Krüger, A. The international politics of sport in the twentieth century. Londres: E\& FN Spon; Nova lorque: Routledge, 1999.

5. Mathys, F. K. “Those controversial games of 1906...". Olympic Review, n. 146, p. 694, dez/1979.

6. Menary, S. GB United? British Olympic Football and the end of the amateur dream. Worthing: Pitch, 2010.

7. Giglio, S.S. "COI x Fifa: a história política do futebol nos Jogos Olímpicos". 2013. 518 f. Tese de doutorado em ciências defendida na Escola de Educação Física e Esporte da Universidade de São Paulo (USP), São Paulo, 2013.

8. Dietschy, P. “Violence et supporters de football en Europe jusqu'au début des années 1960 : I'exemple de l'Italie". In: II Simpósio Internacional Hooliganismo e Copa de 2014, 2012, Rio de Janeiro/Campinas: CPDOC/FGV - PPGEF/FEF/Unicamp, 2012, p. 1-20.

9. Les Jeux de la VIII Olympiade Paris 1924, Rapport Officiel. Les recettes et les spectateurs du football (Stade de Colombes, Stade Pershing, Stade Bergeyre, Stade de Paris), p. 318-319.

10. Vigarello, G. "Estádios: o espetáculo esportivo das arquibancadas às telas". In: Corbin, A.; Courtine, J.-J.; Vigarello, G. História do corpo Mutações do olhar: o século XX. $3^{a}$ ed. Petrópolis: Vozes, 2009. p. 450.

11. Giglio, S.S. "COI x Fifa: a história política do futebol nos Jogos Olímpicos". 2013.518 f. Tese de doutorado em ciências defendida na Escola de Educação Física e Esporte da Universidade de São Paulo (USP), São Paulo, 2013.

12. 27th IOC Session, Amsterdam, 1928, p. 146-147. Essas informações também estão presentes no Bulletin Officiel du Comité International Olympique, n. 11, outubro de 1928. The meeting of friday morning 3rd August.

13. Giglio, S. S.; Rubio, K. "As relações entre o COI e a Fifa e a formação da Copa do Mundo de Futebol". In: Giglio, S. S.; Silva, D. M. M. da. (orgs.). O Brasil e as Copas do Mundo: futebol, história e política. São Paulo: Zagodoni, 2014.

14. Outras notícias sobre a XI Olympiada. Ainda o incidente verificado entre as representações de futebol da Aústria e do Perú - Os sulamericanos deixaram Berlim, com destino à Colônia - Espera-se uma resolução favorável para o caso - 0 remador brasileiro Celestino Palma, do C. R. Tietê-São Paulo, classifica-se em terceiro lugar nas provas de esquife. O Estado de S. Paulo, 13 de agosto de 1936, p. 6; Os Jogos Olympicos de Berlim. Os peruanos abandonam definitivamente o certame - A japoneza Mayahata triunfa na final dos 200 metros, de peito - O Brasil obtém a segunda colocação numa eliminatória de auterrigues a 4 - 0 Japão venceu o revezamente aquático em 800 metros - Cresce o vulto do incidente originado pelo embate Aústria VS. Perú, de futebol. Folha da Manhã, 12 de agosto de 1936, p. 11.

15. Bourdieu, P. "Como é possível ser esportivo?". In: Bourdieu, P. Questões de sociologia. Rio de Janeiro: Marco Zero, 1983.

16. O amadorismo e os Jogos Olímpicos. O Estado de S. Paulo, 4 de agosto de 1956, p. 11 